\title{
ПРИНЦИПЫ И МЕТОДЫ УПРАВЛЕНИЯ ДЕБИТОРСКОЙ ЗАДОЛЖЕННОСТЬЮ НА ПРЕДПРИЯТИЯХ
}

\author{
(c) 2020 Садыкова Лилия Гайсаевна \\ кандидат экономических наук, доцент \\ Стерлитамакский филиал Башкирского государственного университета, \\ Россия, Респ. Башкортостан, Стерлитамак
}

На сегодняшний день важной задачей на предприятии является эффективное управление дебиторской задолженностью, направленной на оптимизацию его размера и своевременную инкассацию долга. Дебиторами являются, как правило, хозяйственные контрагенты, которые задолжали фирме-кредитору. Увеличение дебиторской задолженности свидетельствует об отрицательной тенденции: она отвлекает средства из оборота, вследствие чего финансовое состояние организации может пошатнуться.

Ключевые слова: задолженность, дебитор, лимит, контроль, управление, принципы управления, методы управления, управление дебиторской задолженностью.

В современных условиях развития экономики наблюдается замедление платёжного оборота организаций, это приводит к росту дебиторской задолженности. С данной целью принято классифицировать дебиторскую задолженность по признакам (рис.1).

Дебиторская задолженность включает в себя: задолженность поставщиков, подотчетных лиц, покупателей, налоговых органов, внебюджетных организаций. Последние два становятся дебиторами, если данная фирма переплатила, внесла аванс. Дебиторская задолженность возникает в случае, если товар (или услуга) проданы, а денежные средства не получены.

На текущий момент состояние дебиторской задолженности для многих компаний является особым препятствием на пути к достижению эффективной работы оборотного капитала. Как правило, возникновение нездоровой задолженности связано с неосмотрительностью кредитной политикой предприятия к должникам, неразборчивым выбором партнёров и стремлением нарастить объемы продаж.

Управление дебиторской задолженностью подразумевает контроль за оборотными средствами предприятия. Чтобы обеспечить благоприятный климат, необходимо уделять внимание при отборе потенциальных заказчиков и клиентов. Как правило, это определяют при помощи критериев: уровень финансовой устой-

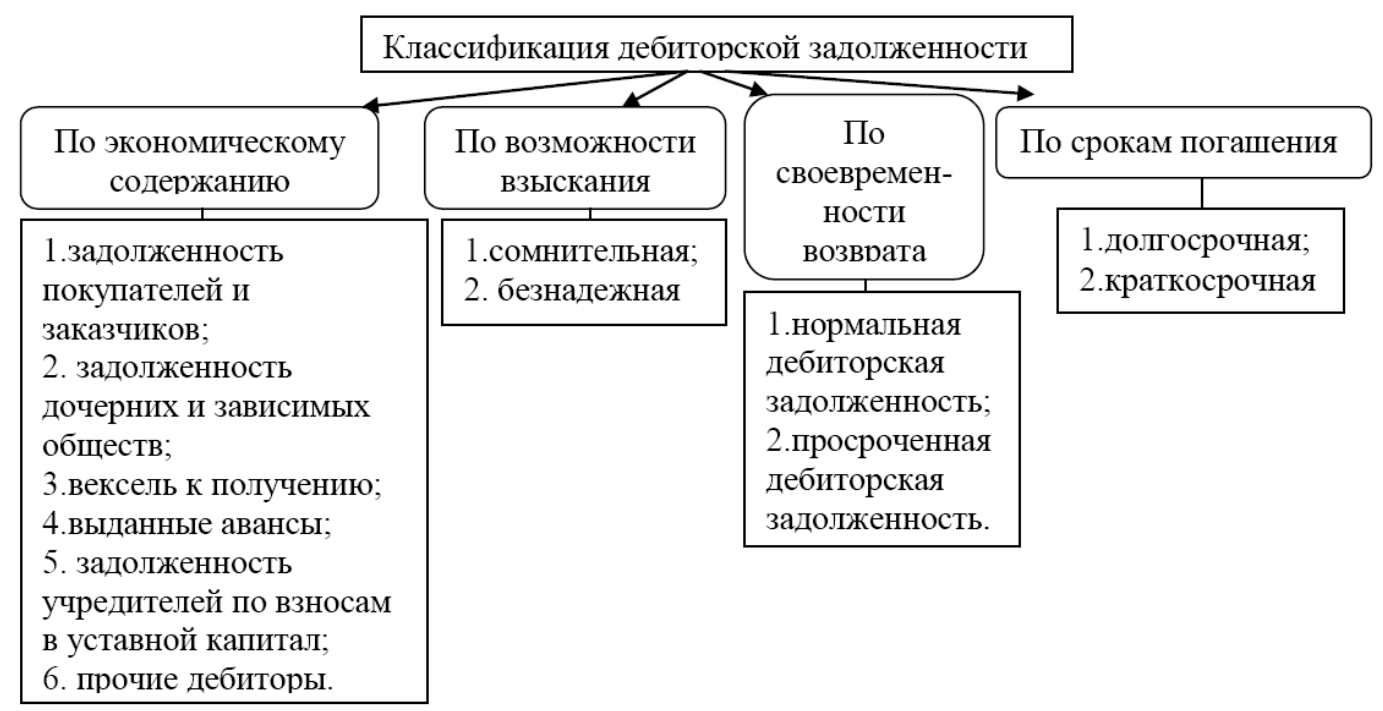

Рuc. 1. Классификация дебиторской задолженности 
чивости, текущей платёжеспособности, соблюдение платёжной дисциплины в прошлом, прогнозные финансовые возможности заказчика по оплате запрашиваемого объёма или объёма работ, экономические и финансовые условия предприятия-продавца (степень нуждаемости в денежной наличности) и другие.

Величина дебиторской задолженности определяется различными факторами, в том числе принятой в экономическом субъекте системой расчетов. Этот фактор особенно важен при формировании системы управления дебиторской задолженностью.

Перед тем как сформировать политику управления дебиторской задолженностью, необходимо рассмотреть основные принципы, на которых должна базироваться вся система управления:

1. Принцип постоянной готовности. Данный принцип подразумевает постоянную готовность менеджера к возможному ухудшению конъюнктуры на товарном и финансовых рынках. На деятельность фирмы оказывает существенное влияние неопределенность рыночных взаимоотношений, что отражается в фактически приписанном кризисном характере развития бизнеса, а, следовательно, при управлении дебиторской задолженностью менеджер должен быть постоянно готов к быстрым ответным реакциям.

2. Принцип гибкости (вариативности). Этот принцип также вытекает из неопределенности, существующей на рынке. Он заключается в необходимости постоянного мониторинга финансового состояния предприятия и экономической конъюнктуры. Постоянный мониторинг позволяет постоянно корректировать объемы и условия коммерческого кредита, предоставляемого дебиторам. Реализация этого принципа предполагает, что подготовка каждого управленческого решения в сфере управления дебиторской задолженности должна учитывать различные управленческие альтернативы.

3. Принцип динамизма. Как и предыдущий, этот принцип вытекает из неопределенности рынка. Формируемые управленческие альтернативы должны быть реализованы своевременно, что на практике подразумевает высокий динамизм принятия решений.

4. Принцип финансовой заинтересованности. Данный принцип заключается в том, что сформированная политика управления деби- торской задолженности и ее постоянная корректировка должна быть нацелена на рост финансовых показателей и, главным образом, на увеличение объемов реализации.

В целом методы управления дебиторской задолженностью можно сгруппировать по следующим категориям: экономические мероприятия анализа и учета дебиторской задолженности, правовые меры, организационноуправленческие меры, меры по обеспечению общей безопасности.

$\mathrm{K}$ первой группе мероприятий можно отнести постоянный анализ и контроль за состоянием счетов, задержки оплаты контрагентами, определении причин такой задержки; проведение оценки уже имеющейся у предприятия дебиторской задолженности, проведение ее классификации и оценки; мониторинг финансового состояния контрагентов и прочие.

К правовым мерам анализа и учета дебиторской задолженности можно отнести контроль за наличием необходимых расчетных документов, а именно счетов, накладных, актов приемкисдачи работ и других; контроль за изменениями условий договоров с контрагентами.

Организационно-управленческие методы направлены на мониторинг за наличием информации по исполнению договора контрагентами, а также создание системы, позволяющей своевременно отслеживать исполнение условий договора должниками.

К четвертой группе мер можно отнести проведение работы с недобросовестными должниками, а также любую деятельность по предотвращению угроз деятельности организации.

Для предотвращения роста дебиторской задолженности на предприятии, можно предложить следующие приемы и способы:

Необходимо создать систему оценки дебиторов исходя из их надежности и платежеспособности, а также уровня риска неплатежа каждым конкретным дебитором. Для надежных и проверенных контрагентов необходимо разработать систему скидок и поощрений, а для контрагентов, риск неплатежа которых велик, систему минимизации этого риска, например с таких контрагентов можно брать пятидесяти или стопроцентную предоплату, или же ввести ограничения по отгружаемой продукции. Для должников, которые часто просрочивают платежи, необходима система штрафов.

Контролем за уровнем уже имеющейся де- 
биторской задолженностью должен заниматься специальный отдел или же специальная программа, которая будет оценивать ее размер и качество, а также соответствие реальной задолженности и отраженной в документах.

Еще одним способом обезопасить себя от большого объема дебиторской задолженности является создание резерва по сомнительным долгам.

Часто предприятиями используются такие инструменты рефинансирования дебиторской задолженности, как факторинг и форфейтинг.

Суть факторинговой операции заключается в ее продаже банку или другому кредитному учреждению по дисконтной цене, в то время как в будущем они предъявляют ее к погашению в полном объеме.

K преимуществам факторинга можно отнести следующие: привлечение финансовых ресурсов, перенос рисков, связанных с невозвратом платежа на другого финансового агента, ликвидация существенных кассовых разрывов, возникающих при длительной отсрочке платежа контрагентом. Недостатком факторинговой операции являются только дополнительные расходы продавца.

Форфейтинг является одной из разновидностей покупки долга. В отличие от факторинга, форфейтинг как правило используется в крупных сделках, например при продаже крупных объектов недвижимости. Кредитование при операции форфейтинга происходит на длительный срок, что отличает его от кратковременных сроков при факторинге. Как и при факторинговой операции, основным преимуществом форфейтинга является «застрахованность» от неплатежей.

Эффективное управление дебиторской задолженностью относится к необходимым условиям успешной работы фирмы, так как оно создает предпосылки для быстрого роста бизнеса и увеличения финансовых возможностей фирмы. Ускоряется товарооборот, аккумулируются свободные средства, вовремя оплачиваются необходимые счета. Неправильное установление сроков и условий кредитования, не предоставление скидок при досрочной уплате клиентами счетов, не учет других рисков могут привести к резкому росту дебиторской задолженности.

Именно поэтому необходимо регулировать и контролировать размер дебиторской задолженности, уделяя особое внимание следующим направлениям: проведение аналитической работы для всестороннего анализа качества и степени ликвидности задолженности; ускорение платежей; совершенствование системы расчетов; формирование резервов по сомнительным долгам; применение факторинговых операций; грамотная политика по взысканию дебиторской задолженности; построение гибкой системы оплаты; контроль за состоянием расчетов с дебиторами; автоматизация расчетов. Все эти меры будут способствовать снижению размера дебиторской задолженности и недопущению образования безнадежной дебиторской задолженности.

Работа с дебиторской задолженностью, то есть процесс управления ею, является важным моментом в деятельности любого предприятия и требует пристального внимания руководителей и менеджеров. Поэтому был разработан алгоритм управления дебиторской задолженностью, представленный ниже.

1. Ретроспективный анализ текущей дебиторской задолженности (оценка величины и состава задолженности)

2. Формирование кредитной политики предприятия по отношению к контрагентам

3. Расчет оборотного капитала для определения продолжительности финансового цикла.

4. Разработка системы оценки кредитных условий контрагентов.

5. Разработка процедур взимания дебиторской задолженности

6. Применение на предприятии эффективных мер осуществления контроля возникновения и погашения дебиторской задолженности.

Дебиторская задолженность предприятия является одним из главных источников формирования денежных средств для погашения своих долгов именно по краткосрочным обязательствам.

Существует множество способов регулирования дебиторской задолженности, однако, хотелось бы остановиться на самых распространенных методах и дать им краткую характеристику.

1. Зачет взаимных требований. В ст. 410 ГК РФ оно определяется как частичным или полным погашением одного обязательства посредством другого, встречного. Существуют случаи недопустимости зачета: невозможен зачет при возмещении вреда, причиненного жизни или здоровью; при пожизненном содержании; при взыскании алиментов, при задолженности, по 
которой истек срок исковой давности. При этом методе, организациям необходимо составить акт сверки, а затем сторона-кредитор направляет заявление о проведении взаиморасчетов должнику.

2. Новация долга. Такой метод предполагает, что в процессе переговоров при согласии обеих сторон происходит замена первоначального обязательства другим долговым обязательством с иными условиями. Для правомерного подтверждения этого решения составляется договор новации долга.

3. Отсрочка платежа. Способ предусматривает погашение задолженности, при котором внесение полной суммы переносится на более поздний срок.

4. Предоставление скидок. При этом способе, сумма задолженности пересматривается, и выставляется меньшая сумма, чем была первоначально. Это делается для того, чтобы должник как можно быстрее рассчитался с кредитором.

5. Лимит на стоимость отгруженной продукции. Чтобы это определить предельный лимит дебиторской запрашивается информация для определения адекватности каждого дебитора: сопоставление данных бухгалтерской отчетности о взаиморасчетах и задолженности.

Процесс планирования и контроля дебиторской задолженности - это важный аспект любого предприятия, которое требует поэтапной системы ее регулирования. Правильно составленный план и его реализация способны в полном объеме погасить свои обязательства, наладить цикл свободных оборотных средств, что способствует созданию репутации ответственного и надежного партнера.

\section{Библиографический список}

1. Павлюченко Т.Н., Калюгина И.В. Управление дебиторской задолженностью / Т.Н. Павлюченко, И.В. Калюгина // Современная экономика развития. 2018.-№ 2.- С. 37.

2. Смородина Е.А., Мурашев Н.Н. Дебиторская задолженность на предприятии: методы анализа и управления // Молодой ученый. - 2019. - № 30.- C. 71-73. - URL https://moluch.ru/archive/268/61759/ (дата обращения: 24.01.2020).

3. Жулина Е.Г. Управление дебиторской задолженностью в системе методов управления конкурентоспособностью предприятия / Е.Г. Жулина // Межвузовский сборник научных статей. 2016. -№ 18. С. 81-83.

4. Гетьман В.Г. Специфика оценки дебиторской и кредиторской задолженностей предприятия // Международный бухгалтерский учет. 2015. № 31. С. 12-13. 